\title{
Modelo alternativo de Governança num espaço insular português. 0 caso paradigmático da administração educativa da região autónoma da Madeira
}

\author{
Alternative model of Governance in Portugal. The paradigmatic case of the \\ educational administration on madeira island \\ Modelo alternativo de la Gobernanza en Portugal. El caso paradigmático de la \\ administración educativa de la comunidad autónoma de Madeira
}

JOSÉ EDUARDO MAGALHÃES ALVES

Resumo: Com o esgotamento do papel tradicional do Estado, desponta a Governança como uma fórmula possível de implementação de estratégias de mudança tendo em vista aproximar as decisões através da Nova Gestão Pública, traduzida na superação do centralismo. Ao arquipélago da Madeira, após um processo de regionalização da educação iniciado em 1979, centrado quase apenas em transferência de competências do Estado, coloca-se hoje o desafio de poder seguir um caminho de (re)construção de políticas educativas regionais, nas matérias de governação regional, que convoque todos os atores escolares a intervir.

Palavras-chave: Governança; Administração educativa; Autonomia regional

\begin{abstract}
With the exhaustion of the traditional role of the State, Governance emerges as a possible formula for implementing new strategies of change, with the New Public Management, translated in the overcoming of centralism. In Madeira, after a process of regionalization of education, begun in 1979, centered almost exclusively on the transfer of competences of the State, the challenge is to be able to follow a (re)construction of regional educational policies which calls on all school actors to participate.
\end{abstract}

Keywords: Governance; Educational Administration; Regional autonomy

Resumen: Con el agotamiento del papel tradicional del Estado despunta la Gobernanza, como una fórmula posible de implementación de estrategias de cambio, con el fin de aproximar las decisiones a través de la Nueva Gestión Pública, traducida en la superación del centralismo. A la isla de Madeira, tras un proceso de regionalización de la educación, iniciado en 1979, centrado casi en transferencia de competencias del Estado, se plantea hoy el desafío de poder seguir un camino de (re)construcción de políticas educativas regionales, en las materias de gobernanza regional, que convoque a todos los actores escolares a intervenir.

Palabras clave: Gobernanza; Administración educativa; Autonomía regional 


\section{INTRODUÇÃO}

Desde os primórdios, o estudo e a análise da Administração Pública surgem como uma temática no cruzamento, primo entre a Ciência Política e o Direito, depois entre a Gestão Pública, a Economia Política e a Política e, mais proximamente, a Governação. Diremos, na senda de Moreira e Alves (2008), que os argumentos justificativos para tal dicotomia epistemológica de análise das ciências sociais estão no repúdio dos politólogos pelos assuntos internos, aliado ao caráter prático da formação dos denominados "administradores da coisa pública", ao que se associa a tradição grega e romana na política e nas administrações públicas do mundo ocidental.

Mas, hoje, coloca-se de novo e, até, com extrema acuidade, em face dos novos desafios, o problema central em termos de "grau desejável" de influência da Política na Administração Pública. Um equilíbrio, em última instância, que não pode ser visto como inseparável dos aspetos históricos e institucionais, que tecem a narrativa em cada país e, dentro deste, a forma como os seus territórios acompanham esse processo, obrigando assim a recentrar o problema no exato sentido em que as políticas públicas são cada vez mais determinantes (EASTON, 1975; NAGEL, 1980).

Se estas perspetivas centram o papel inquestionável do Estado enquanto tutela da ação pública, historicamente, poder-se-á afirmar que terá sido com a denominada crise do Estado Providência (Welfare State), que começam a surgir, em finais dos anos 70 do século passado, críticas à dimensão e ao custo desse mesmo Estado, acrescidas mesmo da sua ineficácia no intervencionismo governamental do setor público, criando aquilo que alguns, como Bilhim (2013), apontam como favoráveis ao aparecimento de mudanças sustentando novos modelos de "gestão pública" e que induzem a adoção de práticas do setor privado, consideradas mais eficientes, tendo em vista a consecução de objetivos organizacionais (LHÉRISSON, 1999).

A problemática da governação, da governabilidade e/ou da governação do nosso tempo tornou-se, portanto, cada vez mais atual, em linha com aquilo que foram as condições colocadas pelo "consenso de Washington", do FMI e da Comissão Europeia, sob a forma de diversas iniciativas e sempre com o denominador comum de better regulation.

De relevante é constatar que começou a desenvolver-se no último quartel do século XX um "corpus teórico" sobre as boas metodologias e as melhores práticas de governação, visando a densificar o tecido da migração para um "novo" 
Estado Regulador de elevada qualidade, aquilo que Pierre e Peters chamam de: "uma nova forma de pensar sobre as capacidades do Estado e as relações entre o Estado e a Sociedade” (PIERRE; PETERS, 2000, p. 50).

Estão assim lançadas as condições para o surgimento de um movimento a favor de uma "Nova Gestão Pública", que, embora surgindo em tempos de valorização do mercado e, mesmo, de defesa da privatização dos serviços públicos, foi também visto como alternativa às propostas para a redução do tamanho do governo ou de diminuição dos gastos, já que, de todas as formas, continuaria a existir um sector público dedicado a oferecer uma grande quantidade de serviços, que os assinalados efeitos anteriormente apontados faziam antever. Aliás, esse movimento, preocupado com a defesa de uma forma de governo mais parecido com o sector privado acaba, também ele, por animar uma "terceira via" de reforma do Estado e muitos programas de modernização da Administração Pública ${ }^{1}$. Esse movimento, cada vez mais aceito pela comunidade acadêmica com a denominação de New Public Management (HOOD, 1991), acabou por ganhar corpo em muitos países europeus, tendo num documento da OCDE (1997), a propósito da necessidade de formulação e implementação de estratégias de mudança, com base nesta Nova Gestão Pública, uma boa síntese, pela sua antecipação e lucidez prospetiva:

Ainda, que não exista um modelo único ou o ideal de reforma, os objetivos a ter em conta são, em geral, uma maior atenção aos resultados e uma melhor relação qualidade/preço; transferências de competências e mais flexibilidade; o reforço da responsabilidade e do controlo; uma orientação para o cliente e para o serviço; uma maior capacidade de definição das estratégias e das políticas; a introdução da concorrência e dos mecanismos de mercado, e a alteração das relações com outros níveis da administração pública (OECD, 1997).

Neste artigo é nossa preocupação identificar, portanto, as mutações pelas quais o Estado atravessou desde o final do passado século. Esse, que fica sobretudo marcado pelo esvaziamento do seu papel tradicional e, muito particularmente, ultrapassada uma visão de governação clássica de Administração Pública, conduzida pelos Governos através de políticas públicas centrais. $\mathrm{Na}$ realidade, essa visão revela-se, hoje, cada vez mais incapaz de dar resposta cabal aos reais problemas, sociais, económicos, culturais e ambientais; quer, ainda, responder de forma próxima e adequada aos efetivos problemas regionais e locais dos territórios insulares. Desponta, portanto, a necessidade de novas formas de governação, a propósito da qual a OCDE, como se viu, vaticina a Governança

1

Uma corrente reformista que se caracteriza por ter um discurso pós-burocrático assente em conceitos como enfoque no cliente ou qualidade do serviço. 
como uma fórmula possível de implementação de estratégias de mudança, tendo em vista aproximar as decisões através de mecanismos políticos territoriais de descentralização e autonomia, traduzidos numa superação do Estado centralista, por um modelo de governação partilhada de poder e autoridade.

Este nosso estudo está dividido em quatro partes fundamentais, para além desta Introdução. A primeira seção problematiza o tema da Governança enquanto modelo evolutivo de governação pública. A seção seguinte transportanos para a afirmação dos conceitos definidos na seção anterior, no denominado mundo da educação. Isto porque, na Educação, os desafios colocados pelo sucesso e pela qualidade obrigam a repensar os modelos clássicos da governação, justamente onde a autonomia escolar pode ajudar a desenhar complexos sistemas de Governança, com a partilha de políticas educativas, a vários níveis, iniciando um movimento global de reforma educativa.

Aqui chegados, na seção terceira, preocupa-nos refletir sobre a Ilha da Madeira, naquela que é a questão principal. Assim, analisamos aqui, a governação educacional na atualidade, constatando que, após o processo de autonomia e regionalização iniciado em finais do século passado, é crucial a necessidade de seguir-se um caminho próprio e autónomo de (re)construção de políticas educativas regionais, nas matérias de governação regional, que invoquem sua natureza de Região insular europeia; tendo-se presente também, que este é um momento onde a abertura de um ciclo gestionário se perspetiva (em linha com a Nova Gestão Pública) e no qual assinalamos exemplos práticos governativos regionais, onde essa dimensão avulta.

Finalmente, na última seção, apontamos nossas convicções, que vão no sentido de que, não obstante a assinalada forte ligação ao sistema educativo nacional português, deve-se afirmar uma matriz regional, através de um percurso evolutivo alternativo, que não descure todavia, uma path dependence (PIERSON, 2000), com vincado pendor político/sociológico, iniciada nos 40 anos de autonomia regional em Portugal.

\section{GOVERNANÇA}

O futuro da governabilidade dos territórios antecipa motivos da "emergência" de um novo modelo de governação (JESSOP, 2000), pelo que, concomitantemente à reorganização da maioria dos Estados, foi-se revelando indispensável também opor aos efeitos do centralismo das decisões governativas, da excessiva legislação e da burocracia a operacionalidade dos próprios sistemas políticos (FERREIRA, 2007). Nesse complexo, acabam avultando mesmo, com 
merecimento, as autonomias políticas/administrativas dos territórios, que não atingem a independência, mas revestem formas peculiares de descentralização (caso da Ilha da Madeira, em Portugal).

Assistem-se, nesse desenrolar, a processos de descriminação (GIBBS, JONAS et al., 2001) ou rescaling (BRENNER, 1999) do próprio Estado fundador, onde ocorrem, em maior ou menor escala, movimentos de transferência de poder com sentido variável. Isto é, a partilha para cima, através de uma maior ligação do Estado a entidades supranacionais; de forma lateral, através de transferência de competências para organizações e agências governamentais; e, para baixo, à escala regional e local, através de entidades que aumentam sua relevância nos processos de governação. Paralelamente, as várias transformações a que se assiste no Estado nacional conduzem também a um progressivo hollowing-out do próprio Estado (RHODES, 1996). Isto é, funcionalmente, o Estado apesar de manter sua soberania nacional assiste a um seu "esvaziamento", naquilo que é a coordenação e mesmo definição de políticas, que progressivamente conduzem a uma transferência de poder para escalas intermédias.

É no contexto dessas transformações que assume relevo, portanto, o conceito de Governança, como alternativa de organização política e modelo de governabilidade. Apesar de se tratar de conceito relativamente recente, que se vem contrapondo aos conceitos de Governo (government) ou Governação (governing) (GRAHAM; AMOS, et al., 2003), acaba sendo já um conceito abundantemente tratado e com múltiplas abordagens e entendimentos, traduzindo diferentes trajetórias nas agendas de governação de muitos países. Epistemologicamente, está conexo com aspetos de organização do próprio território, onde se aplica a tomada de decisão das políticas públicas. Doutrinariamente, está próximo sempre das teorias que apontam para a necessária aproximação do Estado às pessoas e das interdependências entre setores (INNES; BOOHER, 2003), levando também aos conceitos de democracia participativa e aos modelos de governação colaborativa (ANSELL; GASH, 2008), que lançam o debate sobre a importância e regulação da ação coletiva (LE GALÈS, 2002; CARS, HEALEY, et al., 2002).

Não obstante a mencionada complexidade, é consensual entre os autores, que não se tratando de um sinónimo de Governo, a Governança pressupõe uma evolução dos modelos tradicionais, em ruptura com os princípios, mecanismos e procedimentos de gestão/organização pública (RHODES, 1996), traduzindo-se assim, fundamentalmente, na transformação dos modos de governação associados ao Estado burocratizado do Welfare State para um modelo de governação associado a uma visão mais empresarialista e privada (COAFFEE; HEALEY, 2003); ou até, simplesmente, ao abandono de estruturas de governação centralizadas e hierárquicas (BULL; JONES, 2006). 


\section{GOVERNANÇA EM EDUCAÇÃO}

A Organização para Cooperação e Desenvolvimento Econômico (OCDE), através do Programme for International Student Assessment (PISA), tem tido um dos contributos mais relevantes para disseminar as políticas públicas, depois consubstanciadas em práticas, que os países vão desenvolvendo um pouco por toda a parte, com realce sobre a autonomia escolar. Aliás, esta dimensão só por si tem vindo inclusive a ser apresentada, ela mesma, como boa prática, para melhorar o sucesso escolar (BONAL; TARABINI, 2013) e para a redução do abandono escolar precoce (GARCIA; DEL CAMPO, 2012), itens relevantes como indicadores internacionais na aposta de melhoria educacional a nível europeu (COMISSÃO EUROPEIA, 2017). Barroso, nesse sentido, considera mesmo, acutilantemente, que só por si, por detrás da autonomia das escolas, esconde-se uma estratégia de reforma (BARROSO, 2004), sendo que a referida autonomia das escolas pode derivar, ela mesma, por seu lado também, em políticas e práticas, que podem ter diferentes impactos sobre a qualidade e a equidade educativa e daí a sua extrema pertinência no estudo (VERGER; NORMAND, 2015).

$\mathrm{Na}$ realidade, os resultados apresentados pela OCDE evidenciam que os países onde as escolas dispõem de maior autonomia, o rendimento e, nalguns casos mesmo, o sucesso, são maiores, estabelecendo-se aqui uma clara aproximação entre conceitos e políticas públicas no setor educativo. "Os dados PISA mostram que a relação entre o rendimento das escolas e o seu nível de autonomia na gestão dos recursos é positiva em alguns países e negativa noutros" (OECD, 2011, p. 2).

De facto, tanto na doutrina dedicada a estas matérias, como na governação na educação, em si mesma, assiste-se um pouco, por todo o lado, a um entendimento sobre a implementação de políticas públicas, na área educativa, assumindo-se que se trata de um processo linear tipo top-down ou bottom-up, sem grandes divergências (THRUPP; EASTER, 2012). Não obstante, hoje, as políticas públicas devem aplicar-se em contextos reais escolares, isto é, em escolas que funcionam dentro de um tempo e espaço educativo próprio. Mais, entre as escolas existem diferenças de recursos a vários níveis e elas dispõem de atores com diferentes interesses (FALABELA, 2016), levando por exemplo Ball a considerar, que este conflito de interesses, dentro da escola, surge como uma luta entre interesses e ideologias como se de uma arena se tratasse (BALL, 1989).

Ora, essa realidade complexa, onde as escolas são vistas como “organizações micropolíticas” (BALL, 1989; BLASE, 1991; MARSHALL; SCRIBNER, 1991), remete-nos para a importância de considerar que o processo de implementação da política educativa, longe de resultar numa interpretação e aplicação direta e homogénea em todas as escolas, deriva de uma interpretação e 
aplicação ampla com múltiplas reinterpretações e matizes. Particularmente, tratase de ter em consideração aquilo que Ball, Maguire e Braun (2012) avisadamente designam pelo conceito de enactment aplicado à administração educacional. Isto é, a forma como as escolas desenvolvem as políticas nos contextos educativos reais passa, assim, por um processo de interpretação e tradução das políticas educativas em práticas, isto é, sua recontextualização e aplicação, por parte dos atores escolares, que se movem nos contextos das escolas. Aqueles autores alertam ainda, a propósito de contextos, para a história da escola, dos seus recursos e infraestruturas, dos processos e dos envolvimentos, bem como toda a cultura organizacional onde se incluem as pessoas e Keddie (2014) assinala a relevância do contexto em que se situa a escola, para explicar as diferenças dos processos internos, as interpretações e os resultados que decorrem das políticas.

Releva portanto, trazer para a administração educacional o conceito aludido da Governança. É que, também aqui, a questão da interação entre entidades múltiplas e atores diversos se coloca, quiçá, até mais relevantemente, a um nível mais sistémico de organização da própria administração educacional. Efetivamente, as funções educativas são cada vez menos exclusivas dos Estados (AGRANOFF; MCGUIRE, 2003; BARROSO, 2003; FORMOSINHO, FERNANDES et al., 2005; LIMA; AFONSO, 2002).

Acresce que, num modelo de governo da educação assente na noção do único ator central, as questões de governação e de definição das políticas educativas públicas avultam com base numa delimitação precisa e clara das duas áreas: Política e Administração. No âmbito da Política, chega-se à decisão sobre a formulação dos problemas e dos objetivos de ação. Só após, faz-se apelo a conceitos científicos e técnicos para desenhar as medidas e sua efetiva aplicação. Por essa razão, a fase de implementação, ao contrário da tomada de decisão, é encarada como um processo não público, como uma atividade exclusivamente técnica. Compreende-se portanto, que devam ser entendidas (e mesmo estudadas) a formulação de políticas e a governação tout court, através do mero aperfeiçoamento e da racionalização das próprias políticas, da clarificação de objetivos, da redução do número de intervenientes na própria fase de implementação, e de uma melhor informação, maior monitorização e controlo da atividade (KICKERT; KLIJN; KOPPENJAN, 1997). Diremos que hoje será evidente, como propugna Barroso (2003), que governar na área da educação implica um conjunto múltiplo de organizações e de conexões, sem as quais a concretização das políticas públicas pode ficar comprometida.

Com maior ou menor incidência foram surgindo, no último quartel do século XX, em especial com enfoque nos países de inspiração anglo-saxônica, com destaque relevante para Inglaterra e Nova Zelândia, alternativas ao modelo 
centralizado da educação. A Nova Gestão Pública apontada, como se viu, pela OCDE como um novo paradigma de organização dos serviços públicos (CHRISTENSEN \& LAEGREID, 2001), tem também uma aportação no âmbito da governação educativa. Aqui, podem alterar-se até de forma drástica (TOLOFARI, 2005), a forma de conceber a governação das instituições educativas e sua autonomia. Princípios, como os da prestação de contas ("accountability") e da gestão baseada em resultados, passam mesmo a ser indicadores determinantes para regular, prover e financiar as escolas. Em rigor, porém, até podemos aditar todo um conjunto de teorias, para além daquela, que analisam o declínio da soberania e da fragmentação institucional do Estado, apontando-lhe alternativas, casos do The New Public Governance, (OSBORNE, 2006); New Governance, (RHODES, 1997); The Public Governance, (SKELCHER, 2005; STEPHEN, 2006).

Importante é reter que a influência dessas novas abordagens, também no "mundo da educação", têm surgido como "uma relativa sincronia das reformas, uma forte similitude entre alguns eixos estruturantes e estratégias adotadas e, mesmo, uma constância argumentativa quanto aos imperativos das mudanças" (LIMA; AFONSO, 2002, p. 7).

Trata-se portanto, de progressivamente ir olvidando uma conceção central de governo em favor de uma atividade de coordenação da vida social garantida por múltiplas entidades, de forma descentralizada e até autónoma, abarcando um cenário de implementação das políticas, que implica um crescente número de relacionamentos entre organizações públicas e não públicas assentando, mesmo, em cruzamentos cada vez mais complexos entre atividades (AGRANOFF; MCGUIRE, 2003), pelo que a consideração de Governança, também na educação, ganha relevo. Aliás, a mencionada autonomia escolar interconecta-se com o processo mais amplo de reconfiguração dos modos de Governança e de regulação das políticas educativas. De facto, assiste-se a uma passagem da regulação da educação, através de um controlo prévio mediante a aferição pelo cumprimento da lei, para um novo modo de regulação baseado no desenvolvimento dos processos, onde o importante é a qualidade e os sucessos educativos.

Não obstante, vários têm sido os autores, que apontam fragilidades ao modelo trazido por uma nova governação pública para a educação, caso de Dunleavy e Hood (1994), que o designam por "modelo da galinha sem pescoço", numa alusão crítica e dura ao impacto dos serviços públicos serem geridos em excesso ao nível de cada unidade organizacional e de modo insuficiente ao nível do próprio sistema, como uma orientação global. Fundamentalmente, é apontado ao modelo sua clara opção pela adaptação e implementação de políticas públicas com fundamento no setor privado, com o risco do essencial: a menorização dos 
serviços públicos. Isto, justamente, numa dimensão onde a Educação terá, aliás, relevo. E também, num contexto, onde a dimensão económica não pode ser central e, menos ainda, a erosão da prioridade concedida à equidade na definição e implementação de políticas, substituindo-a por uma enfase primacial nas questões de eficiência (BARDOUILLE, 2000; RHODES, 1996).

\section{GOVERNANÇA EM EDUCAÇÃO NA MADEIRA}

Estudos recentes têm-se debruçado, também, sobre um possível alcance para as definições de Governança, com enfoque regional. Destaque interessante em Ache, "A Governança, em primeira instância, pode ser simplesmente entendida como as estruturas e as formas pelas quais as regiões são geridas, num sentido administrativo, jurídico, público, privado, local, nacional e europeu. (ACHE, 2000, p. 444).

Fundamentalmente, trata-se de constatar, em linha até com o "princípio da subsidiariedade" (artigo $5^{\circ}, n^{\circ} 3$, do Tratado da União Europeia), relevante para as regiões europeias, que os atores locais conseguem avaliar melhor os problemas da sua região, do que os agentes nacionais ou supraestaduais. Expetativas políticas e sociais geradas pela cooperação possível entre atores regionais em áreas fundamentais e próximas dos cidadãos, casos do emprego, regulação mercado trabalho, e da educação (JANN, 2003; AMOS, 2010).

Reveste-se pois, pertinente, ensaiar uma análise meso (HYDEN; COURT, 2002) que perscrute na realidade governativa educacional insular da Madeira, efeitos de Governança.

Concretamente, depois de um período de consagração da autonomia regional $^{2}$, devemo-nos reportar ao momento atual ${ }^{3}$, grosso modo, decorrente da assinatura pela Madeira com o Estado português, em 27 de janeiro de 2012, de um Programa de Ajustamento Econômico e Financeiro, 2012-2015 (PAEF-RAM), aprovado pela Resolução do Conselho de Governo Regional no 41/2012, de 01 de fevereiro 4 . É propósito declarado deste Programa, mediante o elenco, por vezes exaustivo, que faz das várias áreas da governação regional, impor restrições e

2

A Região Autónoma da Madeira foi criada pela Constituição da República Portuguesa de 1976, tendo merecido na área da educação um processo de transferência de competências do Estado, a partir de 1979, cujo repositório legal consta, fundamentalmente, do Decreto-Lei no 364/79, de 04 de setembro.

3 Este período coincidirá com "um terceiro momento" da governação educativa na Madeira, que começa a "desenhar-se" a partir de 2011, coincidindo com o XI Governo Regional (2011-2015) e depois XII Governo Regional (2015-2019), (ALVES, 2014).

4 Este Programa inclui um conjunto amplo de medidas orientadas para dois objetivos: permitir a consolidação orçamental da Região de forma a restaurar a sustentabilidade das finanças públicas e permitir repor a capacidade de financiamento autônomo. 
limites, objetivamente, na despesa pública. A esse nível, a educação acaba surgindo, assim, no referido PAEF-RAM, como sendo compromisso do Governo Regional em reduzir: "o peso do sector da educação no orçamento regional" (ponto 24.).

Compreende-se portanto, que este marco cronológico inicie um ciclo, donde começa a avultar uma lógica gestionária, mais do que uma política de (re)destribuição de poderes. (LIMA, 1995) . É aqui que se começa a assistir à emergência dos discursos que apelam aos modelos de inspiração e de gestão privadas, particularmente, de cariz empresarial: "importação de lógicas de mercado para os sistemas escolares", em detrimento do político (BARROSO; VISEU, 2003, p.898). O denominado gerencialismo na administração pública e, especialmente, na administração da educação, cujos pilares assentam em princípios da Nova Gestão Pública e em perspetivas da administração pública empresarial, já com manifesta e transversal influência em Portugal (SANTIAGO; MAGALHÃES; CARVALHO, 2005).

Assiste-se na Madeira, neste período, à criação de uma Escola de ensino secundário de natureza profissional pública (Escola Profissional de São Martinho) que, como refere o preâmbulo da sua criação, o Decreto Legislativo Regional $\mathrm{n}^{\mathrm{o}}$ 14/2011/M, de 10 de agosto: "Seja dotada de autonomia administrativofinanceira, consequentemente, imbuída de uma agilização de procedimentos ao nível da gestão, que permita dar cumprimento aos desafios que estão colocados no âmbito do Plano de Desenvolvimento Económico e Social (PDES 20072013 (...)"; e, onde, a gestão privatística é claramente o objetivo, por revestir esta forma de gestão como é referido, de maior agilização procedimental. Cria-se, subsequentemente, o Instituto para a Qualificação, IP-RAM (Decreto Legislativo Regional n ${ }^{\circ}$ 6/2016/M, de 08 de fevereiro), com propósitos iguais aos anteriormente declarados. Não obstante, vai-se até mais longe, num sentido de afirmação da gestão privada, já que, com essa nova opção legislativa, acabará por ficar, ainda, a referida Escola Profissional de São Martinho (entretanto renomeada de Escola Profissional Dr. Francisco Fernandes ${ }^{5}$ ) integrada no referido Instituto (artigo $3^{\circ}$, do Decreto Legislativo Regional n 6/2016/M), constituindo-se uma original estrutura organizacional, que congrega na própria administração uma escola profissional pública.

5 Pelo Decreto Legislativo Regional no 41-A/2012/M, de 08 de fevereiro, a Escola Profissional de São Martinho, passaria a designar-se por Escola Profissional Dr. Francisco Fernandes. 
O exemplo, ainda, da privatização, pela Resolução do Conselho do Governo Regional no 1504/2009, de 16 de dezembro, no caso, da Escola Profissional de Hotelaria e Turismo da Madeira ${ }^{6}$, mediante a concessão da sua gestão a uma entidade privada, por um período de 15 anos, prorrogável por iguais períodos é sintomático deste impulso regional privatístico de índole gestionário.

Com a aprovação do Estatuto de Educação e Ensino Privado da Região Autónoma da Madeira, aprovado pelo Decreto Legislativo Regional nº 15/2011/M, de 10 de agosto, acentua-se o desenvolvimento dessa mesma lógica privatística, no caso por cedência ao ensino privado. Apesar de a rede escolar regional ser predominantemente de natureza pública (na realidade em queda, passando, no período de uma década, de $75 \%$, em 2004 , para $66 \%$, em 2014) constata-se um claro aumento do ensino privado ao longo desse mesmo período, sem embargo de um gradual decréscimo de população estudantil na Madeira (CONSELHO NACIONAL DE EDUCAÇÃO, 2014, p. 34). Estaremos aqui, aliás, perante uma perspetiva que faz denotar a existência, em crescendo, de "operadores privados na rede pública” (HOMEM CRISTO, 2013, p. 85), mediante a abertura, dessa mesma rede, através do princípio de igualdade do financiamento, independentemente da natureza das escolas (artigo 65 ${ }^{\circ}$, do Decreto Legislativo Regional no 15/2011/M).

A outro nível, e tendo por base a Lei 31/2002, de 20 de dezembro, que no desenvolvimento da Lei de Bases do Sistema Educativo transporta para educação uma perspetiva de avaliação das escolas em Portugal, tendente à melhoria da qualidade do sistema educativo, na Madeira, a Portaria no 245/2014, de 23 de dezembro, veio definir, aqui, com um grau de abrangência conceptual até mais amplo, um possível quadro de total aferição da qualidade do sistema educativo regional. Particularmente, é defendido nesse modelo normativo regional, um sistema de dinâmicas de autoavaliação das escolas, convocando a participação de diversos atores implicados no seu funcionamento, mas objetiva, sobretudo, uma lógica gerencialista: prestação de contas pelas escolas. Escolas da Madeira, cujo modelo de organização se assenta num regime organizacional próprio ${ }^{7}$, que lhes consagra total autonomia administrativa, financeira e pedagógica.

6 A Escola Profissional de Hotelaria e Turismo da Madeira ("nascida" em 1967, como "Escola Basto Machado"), transitou para estabelecimento de ensino profissional público, mediante o Decreto Legislativo Regional no 23/98/M, de 18 de setembro.

7 Decreto Legislativo Regional no 4/2000/M, de 31 de janeiro, alterado pelo Decreto Legislativo Regional n²1/2006M, de 21 de junho. 


\section{EM CONCLUSÃO}

O que se assiste de forma evolutiva na Madeira, na área da educação, é no sentido em que a descentralização territorial provocada com a criação da Região Autónoma e, consequente regionalização educativa, traduziu-se num "fragmentar" do modelo de regulação da administração do sistema educativo único e estatal, introduzindo-lhe aquilo que autores como Howlett e Hamesh, designam por "mudanças marginais" (1995, p. 185). Estas mais não são do que alterações, por vezes pouco visíveis ou perceptíveis em termos macro, que não põem em causa a essência do próprio sistema nacional; ou, ainda, uma estratégia para percorrer um percurso próprio (HALPIN; TROYNA, 1995), mediante uma política educativa de education policy borrowing, mesclada com uma education policy learning (DALE, 1999); ou, em linha com Robertson e Dale (2008), através de um "mimetismo", mediante um processo de "regulação partilhada".

Contudo, em momento próximo, a lógica de privatização começa a imperar. Seja no sentido de um desinvestimento progressivo público, seja através de estratégias de concessão, ou mesmo privatização tout court. Esta realidade, tende assim a ser apresentada como coincidente com a própria ideia de reforma da administração pública, na linha de "uma modernização do serviço público" (CHARLOT, 1994, p. 97) No fundo, visa-se à apropriação dos modelos de funcionamento típicos do sector empresarial (ALVES, 2013). Coloca-se pois, aqui, com especial evidência, que merece destaque, uma tônica de política de ação, que enquadra os problemas essencialmente educativos e pedagógicos à "luz de uma visão", que radica numa opção pela lógica de gestão privada, que defende serem os instrumentos de formação, considerados relevantes do ponto de vista econômico e empresarial, que melhor os haverão de resolver (SANTIAGO; MAGALHÃES; CARVALHO, 2005). Até porque, como se viu, sustenta-se que o sistema educativo, no seu todo, tem, também ele, que ser compatível com as orientações dominantes, emanadas de grandes organizações internacionais (OCDE, União Europeia), contribuindo para aquilo que Roger Dale (2001, p.146) designou por: "agenda globalmente estruturada para a educação".

Sem embargo, pensamos que uma nova visão da denominada "coisa pública" deve levar a perceber que a discussão não pode continuar a ser centrada em dicotomias como gestão ou governação. O que mais importa é entender

8

Visível por exemplo, na Madeira, através da criação do "Programa de Reorganização e da Modernização da Administração da Região Autónoma da Madeira (PREMAR)", aprovada pela Resolução n. ${ }^{\circ}$ 1087/2006, de 10 de agosto, do Governo Regional da Madeira. 
que os reais problemas da Administração são sempre multidimensionais e, por isso, mais que o domínio deste ou daquele saber específico, exigem para serem compreendidos, a completa integração de diversos pontos de vista.

$\mathrm{Na}$ realidade, a "teoria da complexidade" acaba reconhecendo a própria natureza da gestão pública como sendo atualmente incerta e fragmentada (HAVERI, 2006), usufruindo concorrentemente da variante sociológica, que releva os aspetos relacionais e estratégicos da organização, à luz da tradicional análise intraorganizacional e sistémica (BILHIM , 2008).

Ao longo das últimas décadas, a consolidação dos estudos sobre as políticas públicas de educação vêm ocorrendo em resposta à centralidade adquirida pela problematização de temáticas relacionadas com as mudanças, nos tipos de regulação da educação e no estilo de competências: científicas, profissionais e burocráticas. Na educação, aliás, essas mudanças nos modos de regulação se traduzem na intensificação dos processos de multiregulação, na complexificação das suas modalidades de execução e no aumento, cada vez mais, da regulação transnacional e hibridismo da regulação nacional e regional (BARROSO , 2006).

De resto, estas tendências têm sido visíveis e começam a chegar a países como Portugal, tradicionalmente mais resistente à mudança, onde novas modalidades de regulação surgiram nas últimas décadas, acabando por emergir, mesmo, no espaço insular da Madeira, como se evidenciou, manifestando-se na adoção de novas formas e processos de governação e gestão da educação (casos de descentralização, contratualização, parcerias público privadas, etc.) e na presença, de algumas intenções discursivas nas políticas públicas, como na autoavaliação e na avaliação externa das escolas (MAROY, 2009; 2011).

Esta fórmula, a que se pode associar um "estilo" de Governança, traz implícita alguns indícios reformadores, marcados pela denominada administração pública de tipo gerencial, claramente de matriz vinculada pelas correntes do New Public Management e onde se denota, até, alguma inspiração ideológica, que coloca a governação pública dependente do mercado, como no caso do ensino privado, e a gestão pública seguindo os princípios da gestão privatística.

Não obstante, todas as assinaladas investidas, a modernização praticada até agora vem reclamando, no entanto, um "novo modelo" de Governança pública na Madeira. Mais orientado a dinamizar o funcionamento das organizações e a conseguir uma melhoria da ação educativa e menos a enfatizar a sujeição a procedimentos estandardizados e fixados em rígidos mecanismos legais e normativos burocráticos de execução (SAHLBERG, 2011). Essa perspetiva avultará como relevante, podendo até daqui emergir um elemento que colmate algumas falhas e regule as relações entre o setor privado e público (em lugar de o querer substituir), máxime, entre a Região e a sociedade/comunidade. É que a 
“aplicação e o impacto da NGP está fortemente condicionada pelas tradições institucionais e as culturas profissionais que prevalecem em diferentes contextos" (VERGER; NORMAND, 2015, p.615).

Quando olhamos atrás para as análises científicas, chegamos à conclusão, de fato, que não há um conceito único de governança pública. Aqui, muito em linha com Kissler e Heidemann, estaremos perante aquilo que Max Weber denominaria de: "conceito ideologicamente amorfo" (2006, p. 480), já que não existe um conceito único e robusto de Governança pública, mas antes uma série de diferentes pontos de partida, epistemologicamente falando, para uma nova estruturação das relações entre o Estado e as suas instituições, sejam públicas (onde incluímos as Regiões Autónomas), sejam privadas.

Perspetivar uma evolução para a dimensão educacional da Autonomia regional na Madeira e, consequentemente, da governação nessa área, dependerá assim, particularmente, da mobilização e do posicionamento que venham a tomar todos os "parceiros educativos com as quais esta tem de conviver" (ALVES, 2013). A todos coloca-se sempre (até de forma renovada), embora se assista a uma continuidade das regras nacionais, a necessidade de uma afirmação regional, que se deverá assinalar em rupturas a nível das práticas (e da forma de colocálas no terreno), o que acaba por conduzir a uma administração autônoma, que resulta, por um lado, com o corte relativamente à cadeia hierárquica do Estado (consequência da autonomia política e administrativa que a Madeira goza); e, por outro, de forma mais construtiva, criando as condições necessárias a conceber e implementar as soluções mais adequadas às necessidades, às expectativas e aos recursos regionais da Madeira, enquanto Região Autónoma (ALVES, 2014).

Ainda, num efetivo quadro teórico de análise, a contribuição trazida por uma abordagem neoinstitucionalista da ciência política, comumente associada ao neoinstitucionalismo histórico (STEINMO; THELEN; LONGSTRETH, 1992), poderá ser convocada. Trata-se de poder recorrer à path dependence ou dependência da trajetória, numa tradução livre. Esse conceito revela que as instituições se desenvolvem ao longo da história e que o processo por meio do qual as instituições modernas são formadas não somente é relevante para explicar o funcionamento da política e situações específicas, como também gera constrangimentos nas escolhas para o futuro. Para Putnam (1996) o conceito de path dependence traz implícito que o lugar a que se pode chegar depende do lugar de onde se veio (PIERSON, 2000). E com isto, acaba-se rejeitando um postulado tradicional da convergência institucional, de que as mesmas forças ativas produzem em todo lugar os mesmos resultados (HALL;TAYLOR, 2003). 
Relevará portanto, colocar em discussão a emergência de uma "visão regional" (ALVES, 2012, p.193), que promova uma política educativa autonômica, que mais determinada do que a decretar uma reforma, construa os alicerces para uma permanente construção organizacional, em contínua articulação entre as diferentes administrações educativas, central, regional e local, bem como com as escolas, não descurando nestas os parceiros, que as integram, e sobretudo os atores que diariamente as fazem funcionar.

De resto, uma das "lições" mais relevantes, que se pode considerar sobre a mudança educacional é que o importante não se pode impor por decreto e, que, quanto mais complexa for a mudança, menos se poderá até impor (FULLAN, 2002).

Atualmente, a realidade nos conduz a encará-la no pressuposto de que os resultados estarão mais do que nos extremos, no equilíbrio que depende da coerência entre os distintos elementos do sistema educativo, como um todo, de modo a assegurar mudança, ou mudanças, com sustentação.

De fato, a construção de uma capacidade regional de afirmação educacional, vinculada à colaboração e ao compromisso dos atores, tem de estar reciprocamente unida com uma responsabilização pelos resultados e como parte de uma política educativa, que aposte decididamente na equidade (BOLÍVAR, 2012). Mais que ter soluções milagrosas para os problemas, sempre indeterminados e imprevistos, uma nova Governança educacional (SAHLBERG, 2011), poderá capacitar (empowering) as escolas, professores, famílias, alunos (HARGREAVES; FULLAN, 2014), para que também suas respostas avultem como determinantes.

\section{REFERÊNCIAS}

ACHE, P. Visions and creativity: Challenge for city regions. Futures, v.32, no 5 , pp. 435-449, 2000.

AGRANOFF, R.; MCGUIRE, M. Collaborative Public Management: New Strategies for Local Governments. Washington, DC: Georgetown University Press, 2003.

ALVES, A.; MOREIRA, J. Cidadania Digital e Democratização Electrónica. Porto: SPI/Principia. 2005

ALVES, J. E. Globalização e Subsistema educativo regional. Políticas educacionais públicas da Madeira. Revista Sensos 8, 4, n², pp. 67-91. 2014 
ALVES, J. E. Passado, presente e futuro da governação educativa na Região Autónoma da Madeira. Revista Portuguesa de Educação, 26(1), pp. 349-376. 2013

ALVES, J. E. Modelos jurídicos de Organização das Escolas. Coimbra: DATAJURIS. 2012.

AMOS, K. Governança e governamentalidade: relação e relevância de dois conceitos cientifico-sociais proeminentes na educação comparada. Educação e Pesquisa, vol. 36, núm. esp., p. 23-38. 2010

ANDERSON, J. Public Policy Making, $3^{a}$ ed. New York: Holt Rinehart and Winston. 1984.

ANSELL, C.; GASH, A. Collaborative Governance in Theory and Practice. J. Public Administration Research and Theory, 18(4), p. 543-571. 2008.

AZEVEDO, J. Avaliação das Escolas: Fundamentar Modelos e Operacionalizar. In Portugal. In C. N. (org.), Avaliação das Escolas: Modelos e Processos, p. 13-99. Lisboa: Conselho Nacional de Educação. 2007.

AZEVEDO, J. Descentralização administrativa e autonomia das escolas. 2015: o ano em que se dá mais um passo em frente. I Seminário Internacional Educação, Territórios e Desenvolvimento Humano: Atas do, Vol. I Conferências e Intervenções (pp. 90-106). Porto: Universidade Católica Portuguesa, 2015.

BALL, S.; MAGUIRE, M; BRAUN, A. How schools do policy: Policy enactment in secondary schools. New York: Routledge, 2012.

BALL, S. J. La micropolítica de la escuela. Hacia una teoria de la organización escolar. Madrid: Paidós/MEC, 1989

BARDOUILLE, N. The transformation of governance paradigms and modalities: insight into marketisation of the public service in response to globalisation. The Round Table, n 353, p. 81-106, 2000

BARroso, J. A escola pública. Regulaşão, desregulação, privatização. Porto: ASA. 2003 
BARROSO, J. Regulação e desregulação nas políticas educativas: tendências emergentes em estudos de educação comparada. In J. Barroso, A Escola Pública: Regulação, Desregulação, Privatização). Porto: ASA. 2003, p. 19-48.

BARROSO, J. A autonomia das escolas: Uma ficção necessária. Revista Portuguesa de Educação, 17(2), p. 49-83, 2004.

BARROSO, J. A regulação das políticas públicas de educação: espaços, dinâmicas e actores. Lisboa: Educa. 2006

BARROSO, J.;Viseu, S. A emergência de um mercado educativo no planeamento da rede escolar: de uma regulação pela oferta a uma regulação pela procura. Educação \& Sociedade. Revista de Ciências de Educação, 24(84), p. 897-921, 2003.

BILHIM, J. Ciência da Administração. Lisboa : Instituto Superior de Ciências Sociais e Políticas, 2013

BILHIM, J. Teoria Organizacional. Estruturas e Pessoas. Lisboa: ISCS, 2008.

BLASE, J. The politics of life in schools: Power, conflict and cooperation. Newbury Park: Sage. 1991

BOLÍVAR, A. Melhorar os processos e os resultados educativos. O que nos ensina a investigação. Porto: Fundação Manuel Leão. 2012

BOLÍVAR, A. Políticas actuales de mejora y liderazgo educativo. Archidona (Málaga): Ediciones Aljibe . 2012

BONAL, X.; TARABINI, A. The role of PISA in shaping hegemonic educational discourses, policies and practices: The caso of Spain. Research in Comparative and International Education, 3, p. 335-341. 2013

BOVAIRD, T.;LÖFFLER, E. Public Management and Governance. London: Routledge. 2003

Brenner, N. Globalisation and reterritorialisation:The re-scaling of urban governance in the European union. Urban Studies, 36(3), p. 431-451, 1999. 
BROADFOOT, P. Education, Assessment and Society. Buckingham: Open University Press, 1996.

BROADFOOT, P. Un nouveau mode de régulation dans un système décentralisé: l'État évaluateur. Revue Française de Pédagogie, no 130, pp. 43-55, 2000.

BULL, A.; JONES; B. Governance and social capital in urban regeneration: A comparison between Bristol a,d Napoles. Urban Studies, 43(4), p. 767-786, 2006.

CANOTILHO, G.; MOREIRA, V. Fundamentos da Constituição. Coimbra: Coimbra Ed., 1991

CARRINGTON, W.; DEBUSE, J. The Teory of Governance \& Accountability. University of Iowa Center for International Finance and Development, 2008.

CARS, G., HEALEY, P. et al. (2002). Urban Governance, Institucional Capacity and Social Milieux. Aldershot: Ashgate.

CHARLOT, B. L' école et le territoire. Nouveaux espaces, nouveaux enjeux. Paris: Armand Colin. 1994

CHRISTENSEN, T.; LAEGREID, P. New Public Management: the effects of contratualism and devolution on political control. Public Management Review, vol. 3, no 1, pp. 73-94, 2001.

COAFFEE, J.; HEALEY, P. (2003). My voice: My place: Tracking transformations in urban governance". Urban Studies, 40(10), p. 1979, 1999.

COMISSÃO EUROPEIA. Europa, 2020. Retrieved from http://ec.europa.eu/ europe2020/index_pt.htm, 2017

CONSELHO NACIONAL DE EDUCAÇÃO. Retrieved from Estado da Educação 2014: http://www.cnedu.pt/content/edicoes/estado_da_educacao/ Estado_da_Educa\%C3\%A7\%C3\%A3o_2014_VF.pdf

DALE, R. Globalização e educação: demonstrando a existência de uma "cultura educacinal mundial comum" ou localizando uma "agenda globalmente estruturada para a educação?”. Educação, Sociedade \& Culturas, 16, pp. 133-169, 2001. 
DALE, R. Specifying globalization effcts on national policy: a focus on the mechanisms. Journal of Education Policy, 14(1), pp. 1-17, 1999.

DUNLEAVY, P.; HOOD, C. From de old public administration to new public management . Public Money \& Management, July-September, p. 9-16, 1994.

EASTON, D. Understanding Public Policy. Englewood New York: PrenticeHall. 1975

FALABELA, A.. Qué aseguran las políticas de aseguramiento de la calidad? Un estudio de casos en distintos contextos escolares. Revista Estudios Pedagógico, 41(1), p. 107-126, 2016.

Fernandes, A. S. Contextos da Intervenção Educativa Local e a Experiência dos Municípios Portugueses. In J. Formosinho, A. Fernandes, J. Machado, \& F. Ferreira, Administração da Educação: Lógicas Burocráticas e Lógicas de Mediação. Porto: Edições ASA, 2005.

FERREIRA, A. Gestão Estratégica de Cidades e Regiões. Lisboa: Fundação Calouste Gulbenkian, 2007.

FORMOSINHO, J. Centralização e descentralização na administração da escola de interesse público. In J. FORMOSINHO, A.; FERNANDES, J. et alii. Administração da Educação: Lógicas Burocráticas e Lógicas de Mediação (pp. 13-52). Porto: ASA, 2005.

FORMOSINHO, J.; FERNANDES, A.; MACHADO, J. FERREIRA, F. Administração da Educação: Lógicas Burocráticas e Lógicas de Mediação. Porto: ASA. 2005

FREITAS DO AMARAL, D. Curso de Direito Administrativo. $3^{\text {a }}$ ed., Vol. I. Coimbra: Almedina, 2006.

FUKUYAMA, F. The end of history and the Last man. New York: The Free Press. 1990

FULLAN, M. Las fuerzas del cambio. Explorando las profundidades de la reforma educativa. Madrid: Akal, 2002. 
GARCIA, E.; DEL CAMPO, M. (2012). ¿ La corresponsabilidad es una estrategia de éxito? Revista de Educación, número extraordinario, pp. 220-248.

GIBBS, D., JONAS , A. et al. Governance, institucional capacity and partnerships in local economic development: theoretical issues and empirical evidence from Humber Sub-region. Transactions of the Institute of British Geographers, 26(1), p. 103-119, 2001.

GRAHAM, J.; AMOS, B. et al. Principles for Good Governance in the 21st Century. Policy Brief, 15, 2003.

HALL, P.; TAYLOR, R. The three versions of neoinstitutionalism. Lua Nova, 58, pp. 193-223, 2003.

HALPIN, D.; TROYNA, B. O. The Politics of Education Policy. Borrowing. Comparative Education, 31(3), 303-310, 1995.

HARGREAVES, A.; FULLAN, M. Capital profesional. Transformar la enseñanza en cada escuela. Madrid: Ed. Morata, 2014.

HAVERI. Complexity in local government change: limits to rational reforming. Public Management Review, 8 (10), pp. 31-46, 2006.

HOMEM CRISTO, A. O. Escola Para o Século XXI: Liberdade e autonomia na educação. 2013. Retrieved from https://www.ffms.pt/upload/docs/escolaspara-o-sec-xxi_vP-LzK4DKkutWL8oLNcV_g.pdf

HOOD, C. Public Management for All Seasons. Public Administration, Vol 69 No1, pp. 13-19, 1991.

HOWlet'T, M.; HAMesh, M. Studying Public Pollicy. Oxford: Oxford University Press, 1995

HYDEN; COURT. Governance and Development. Word Governance Survey, Discussion Paper 1. 2002 
INNES, J.; BOOHER, D. Collaborative policy-making: Governance through dialogue. In M. HAJER; H. WAGENAAR, Deliberative policy analisys: Understanding governance in the network society (pp. 33-59). Cambridge: Cambridge Univ Press, 2003.

ION, J. Le Travail Social à l’Épreuve du Territoire. Paris: Dunod, 2000.

JANN, W. Governance. In EICHHORN, P., Verwaltungslexiton Baden Baden: Aufl, 2003.,p. 449-451.

JESSOP, B. Governance Failure. In G. (ed.), The New Politics of British Local Governance. Basingstoke: Macmillan, 2000, p. 11-32.

KEDDIE, A. It's like Spiderman... with great power comes great responsability: School autonomy, school context and the audit culture. School Leadership \& Management, 34(5), p. 502-517, 2014.

KICKERT, W.; KLIJN, E.-H.; KOPPENJAN, J. Managing complex networks. London: Sage, 1997.

KISSLER, L.; HEIDEMANN, F. 0. Governança pública: novo modelo regulatório para as relações entre Estado, mercado e sociedade? Revista de Administração Pública 40(3), pp. 479-499, 2006.

LASCOUMES, P.; LE GALES, P. Sociologie de l'action publique. Paris: Armand Colin, 2007.

LE GALÈS, P. European Cities. Social Conflicts and Governance. Oxford: Oxford University Press. 2002.

LHÉRISSON, H. Estudio Introductorio. In N. B. Lynn, e A Wildavsky. Administración Pública. El Estado actual de la disciplina. México: Fondo de Cultura Económica. 1999

LIMA , L. Reformar a administração escolar: a recentralização por controlo remoto e a autonomia como delegação política. Revista Portuguesa de Educação 8 (1), pp. $57-71,1995$ 
LIMA, J. A. Redes na educação: questões políticas e conceptuais. Revista Portuguesa de Educação, 20(2), pp. 151-181, 2007.

LIMA, L. (1995). Reformar a administração escolar: a recentralização por controlo remoto e a autonomia como delegação política. Revista Portuguesa de Educação (8)1, pp. 57-71.

LIMA, L.; AFONSO, A. Reformas da Educação Pública: Democracia, Modernização, Neoliberalismo. Porto: Edições Afrontamento, 2002.

Lopes Rodrigues, E. R. (2009). O Estado regulador-Riscos e oportunidades numa envolvente de "multi-level" governação e de globalização. Revista de Ciências Sociais e Políticas (n³), pp. 151-174.

MAROY, C. Em direcção a uma regulação pós-burocrática dos sistemas de ensino na Europa? In D. Oliveira, \& A. Duarte, Políticas públicas e educação: regulação e conhecimento,. Belo Horizonte: Fino Traço Editora. 2011. p. 19-46.

MAROY, C. Convergences and hybridization of educational policies around "post bureaucratic" models of regulation. Compare: A Journal of Comparative and International Education, 39 (1), p. 71-84. 2009.

MARSHALL, C.; SCRIBNER, J. It's all political: Inquiry into the micropolitics of education . Education and Urban Society, 23(4), p. 347-355, 1991.

MINISTRY OF EDUCATION OF FINLAND. Development plan for Education and Research 2007-2012. Helsinki: Ministry of Education, 2007.

Moreira, J. M., \& Alves, A. A. Ciências da Administração, Gestão Pública e Governação em Portugal. In J. M. Moreira, C. Jalali, \& A. A. Alves, Estado, Sociedade Civil e Administração Pública. Para um novo paradigma do serviço público. Coimbra: Almedina. 2008

NAGEL, S. . The Policy Studies Perspective. Public Administration Review, Vol.40,Nº, p. 391-396, 1980.

NÓVOA, A. Evidentemente-Histórias da Educação. Porto: Edições ASA. 2005 
OECD. Education at a Glance 2011. Paris:OECD Publishing, 2011.

OECD. La transformación de la gestión pública. Las reformas en los países de la OCDE. Madrid: Ministerio de la Administraciones Públicas. 1997

OECD. Public management developments survey. Paris: OECD, 1993.

OHMAE, K. (1995). The end of the Nation State, the rise of regional economies. New York: The Free Press.

OSBORnE, D. The New Public Governance? Emerging Perspectives on the Theory and Practice of Public Governance. Londres: Routledge \& Francis Group, 2006.

PIERRE, J.; PETERS, B. . Governance, Politics and the State. Houndmills: Macmillan Press, 2000

PIERSON, P. Increasing Returns, Path Dependence, and the Study of Politics. The American Political Science Review, Vol. 94, Nª 2 (Jun.), p. 251-267. 2000.

PUTNAM, R. Comunidade e democracia: a experiência da. Rio de Janeiro: Fundação Getulio Vargas. 1996

RHODES, R. A. Understanding Governance. Buckingham : Open University Press, 1997.

RHODES, R. A. The New Governance: Governing without Government. Political Studies XLIV, p. 652-667. 1996

ROBERTSON, S.; DALE, R. Researching education in globalising era: Beyond methodological nationalism, methodological statism, methodological educationism and spatial fetishism. The production of educational knowledge in the global era, 19-32, 2008.

SABATIER, P. Political Science and Public Policy . Political Science \& Politics, p. 143, 1991.

SAHLBERG, P. Finnish Lessons: What Can the World Learn from Educational Change in Finland? New York: Teachers College Press, 2011. 
SANTIAGO, R.; MAGALHÃES, A.; CARVALHO, T. O surgimento do managerialismo no sistema de ensino superior poruguês. Lisboa: Fundação das Universidades Portuguesas/CIPES. 2005.

SANTOS, B. Os Processos de Globalização. In B. Santos, Globalização, Fatalidade ou Utopia? Porto : Edições Afrontamento, 2001.

SKELCHER, C. The public governance of collaborative spaces. Public Administration, 83, pp. 573-596. 2005

STEINMO, S.; THELEN, K.; LONGSTRETH, F.. Structuring politics:. New York: Cambridge University.1992.

STEPHEN, P. The New Public Governance. Public Management Review, 8, p. 377-387, 2006.

TAVARES, L. Foresight and Governance: a Problem-oriented Metodology(GOVSIGHT). Inernational Transactions in Operations Research, Vol.10, №2, pp. 169-190, 2003.

TAVARES, L. V. Development Policies in the EU and Technology Foresight: an Experiment in Portugal. Foresight Vol. 4 No2, pp. 33-45. 2002

Thompson, G. Between Hierarchies \& Markets: the Logic and Limits of Network Forms pf Organization. Oxford: Oxford University Press, 2004.

THRUPP, M.; EASTER, A. Research, analysis and insigth into national standards (RAINS) project. Hamilton: University of Waikato, 2012.

TOLOFARI, S. New Public management and education. Policy Futures in Education, V.3, nº1, p. 75-89, 2005;

VERGER, A.;NORMAND, R. Nueva Gestión Pública y educación: Elementos teóricos y conceptuales para el estudio de un modelo de reforma educativa global. Educação \& Sociedade, 36 (132), p. 599-622. 2015. 
JOSÉ EDUARDO MAGALHÃES ALVES é Investigador do Centro de Investigação em Estudos Regionais e Locais, da Universidade da Madeira. Doutor em $\mathrm{Dt}^{\circ}$. Educação/Ciências Trabalho (especialização em modelos jurídicos de escolas) pela Universidade de Cádiz, Espanha. Pós-Graduado em Estudos Europeus, pela Faculdade de $\mathrm{Dt}^{\circ}$. da Univ. de Coimbra. Licenciado em Direito, pela Faculdade de $\mathrm{Dt}^{\mathrm{o}}$. da Univ. de Lisboa. Membro fundador da Associação Regional de Administração Educativa (Madeira),sendo atualmente Vice-presidente da Direção. Membro da Sociedade Portuguesa de Ciências da Educação. E-mail: jemalves1966@gmail.com

Recebido em agosto de 2017 Aprovado em outubro de 2017 